\title{
Research on Innovative Design Method and Application of Architectural Façade Modeling
}

\author{
Feifeng Zhong \\ Guangzhou Nanyang Polytechnic
}

\begin{abstract}
The author through in-depth investigation and access to a large number of literature, in-depth study of the famous architect or architectural firm of architectural innovation masterpiece and the latest innovation new architecture, study from the modeling design fundamental element, Shape structure, building details, building material innovation, material and construction technology, structural technology innovation and other aspects of the building facade modeling innovative design method and applications, it is hoped that it will have certain enlightening function to the future architectural designers in the architectural innovation design.
\end{abstract}

Keywords: Facade modelling; Innovative; Design method; Technique.

\section{Innovative methods of basic elements of modeling design}

Point, line, body is the most basic elements of all architectural facade modeling design, these very basic elements and their composition method are the foundation of building facade modeling. In architectural design, we have to break through the traditional practices. Can refer to the following methods to achieve the design of the basic elements of innovation, so that our design of the building facade modeling with innovation and personality.

\subsection{Innovative methods of 'point'}

We can use architectural nodes (building facade of the junction or turning point, the beginning, middle and end ect of the building axis) to strengthen the junction site of the building visual center. In architectural design, we can highlight the junction point of the building so as to highlight its central position, so that it commands the image of the entire building and makes the building image novel and unique. Let it be the highlight of the building and attract people's attention. For example, the designers of the Shanghai Oriental Pearl TV Tower combined 11 different sizes of spheres together to create the artistic conception of 'large and small pearls dropping onto an enormous jade plate'. These spheres on the tower form the central node of the architectural moiding, making the whole architectural image unique and becoming the landmark of shanghai.

\subsection{Innovative methods of 'line'}

Line can well shape the exterior form of the building in the façade of the building and show the structural beauty of the building. In architectural design, we can use the various free combinations of connection, interlacing, connection, envelopment or support to show the form beauty and structural beauty of the building, so that the architectural appearance is creative.

Polylines and curves can produce novel even peculiareffects in expressing architectural forms. When using the polylines or curve in the appearance of the building, we can use the following methods to innovate: Directional geometric arrangement, juxtaposition arrangement, spatial misalignment arrangement, free rotation of interface, irregular grid variation, random motif replication, dendritic organic derivation, etc. The architectural form of the China Agricultural University Gymnasium designed by the famous Chinese architect $\mathrm{He}$ Jingtang is to use the spatial misalignment of the polylines to form a refreshing architectural form ${ }^{[1]}$.

\subsection{Innovative methods of 'Shape'}

In the architectural form, the body shape of geometric shape is the most basic method of Composition method. If the same and different monomers or complexes are combined in different ways, a rich architectural exterior shape can be produced. In the shape of the modern building, the visual elements of the building are combined into different architectural appearances by means of 
addition, subtraction and deformation on the basic geometric shape.

\subsubsection{Addition}

Addition is mainly to combine different unit bodies into new complexes by shape volume accumulation. In the basic shape accumulation process, the color, shape, size and texture of different shapes can be arranged and combined in space in different orders by means of superposition, addition, insertion, etc., resulting in different building facade shapes. On the basis of the basic form, we can reorganize the building by using additional structures, adding false walls, adding frames and inserting unit bodies to form a rich appearance.

\subsubsection{Subtraction}

Subtraction is the removal or reduction of parts based on a complete fundamental shape or form so as to form a new shape. We can use the methods of splitting, digging, trenching, cutting, and overhead in the proper part of the building to form a new form of construction. The East Hall of the National Gallery of Washington designed by the famous American Chinese architect Ieoh Ming Pei, skillfully used the method of reduction to hollow out different shapes from the front, side, back and top of the building. As a result, On the one hand, the architecture is well integrated with the surrounding environment; the architectural molding is innovative and impressive.

\subsubsection{Deformation}

The deformation includes the body twisting method, the body expansion method and the shape free form. We can use free curve and straight line changes, free curve and straight line change between upper and lower, and the free curve and the straight line change on both sides ${ }^{[2]}$. At the time of architectural design, we can use the methods of rotation, torsion, expansion, contraction, folding, tilting, overturning, exaggerating variation, wave, serration and other methods to transform the architectural shape, making the exterior appearance of the building innovative.

The "small waist" Canton Tower in Guangzhou China has a simple overall shape. The designer used a twisting technique. The 24 steel columns on the tower were twisted counter clockwise from bottom to top. The cross section of each component was changing, making the entire TV tower dynamic and glamorous.

\section{Innovative design methods for architectural details}

When architects are building facades, they can do some articles in the details of the building, such as doors, windows, roofs, cornices, balconies, railings, wall columns, corridors etc., and they can do some changes on their line type, area, proportion, size, color, pattern, high and low, concave and convex, material, advance and retreat, virtual and real, Sparse and dense, light and shadow etc., so that it can make the building facade look flexible and novel.

For example, we can activate the facade image of the building by changing the size or height of the window and the order of the windows. Blinds can also enrich the façade of the building, creating a sense of light and shadow. Irregular windows can make the building's façade look full of personality, but note that the number of irregular windows in the same façade should not be too much, and the form should not be too complicated to avoid conflict ${ }^{[3]}$. The famous French architect Le Corbusier Spent a lot of mental energy on window design when designing the Chapelle de Ronchamp.

He placed windows of different sizes and heights on the outer wall of the church's curved surface. Sunlight shines through these large and small windows, through the stained glass in the window, forming a mysterious indoor environment, allowing people to feel the mysterious religious atmosphere in this distinctive sculpture-like church.

In low-rise buildings, residential buildings or some large public buildings, the roof of our building can use a large-scale cantilevered eave when appropriate, so that not only to connect different forms of building facades into one whole, build a sense of unity and integrity in the facade of the building, and it can make the building to have more cantilevered areas, creating a striking architectural image that makes the building look unique.

\section{Combination of material innovation and construction technology}

Advances in materials and technology have brought more and more creativity to architectural design.

From the ancient times to the present, the rise of various architectural design styles, requires the innovation of materials and technology without exception. From ancient times to today, the rise of various architectural styles has invariably demanded innovation in materials and technology. Innovation in materials and technology brings more innovative conditions to architectural design every time.

The humanization, liberalization, contradiction, complexity and pluralism of postmodernism, the loose and disordered deconstructionism, the misplaced accidents, etc. can all absorb good nutrition in the scientific progress of materials and technology, and penetrate into the architectural culture, thus the great miracle of wonderful workmanship excelling nature ${ }^{[4]}$.

\subsection{Matching and improvement of traditional materials}

In modern society, metal and glass are the main building materials nowadays. If you can improve the traditional materials or use different traditional materials on the façade of the building, you can also make the building's façade shape changeable and novel.

Japanese famous architect Tadao Ando is good at improving traditional materials. He improved the 
extremely rough, solid, heavy concrete into a fine, soft, lightweight fair-faced concrete. Japan's architect guruShigeru Ban, the winner of the Pritzker Prize, is particularly famous for the innovation of unconventional materials such as textiles, bamboo, paper and recycled paper and plastic composites. He is adept at making bold innovations based on traditional methods, and the architectural works he designed always exude an elegant temperament. The Centre Pompidou-Metz designed by him uses a wavy grid roof made of wood strips. The exterior of the Aspen Art Museum designed by him is a wooden screen wall ${ }^{[5]}$.

Whitney Elementary School in Seattle, Washington, USA designed by DLR Group, through the combination of different decorative materials of brick and stone and the exaggeration of the upper window scale, gives the whole building a new and unique feeling. In the Bang Plaza in Melbourne, Australia, the architect combined glass, slate, metal plates and other materials and used the motifs of the polyline elements as carriers to make the building look Brilliant.

Japan's Nagano Olympic Memorial Arena features wood as its main component, and steel and reinforced concrete as its secondary components. This steel-wood hybrid structure creates a novel architectural look. We can also use steel to form a network lattice. For example, the Beijing National Stadium of China (Bird's Nest) uses irregular weaving patterns, and the portal steel frame structure is intertwined and woven together, making the entire building look like a Lively and interesting bird's nest. The facade of the building uses a variety of finishing material to exaggerate and highlight a part of the building, changing the color and image of the Building block ${ }^{[6]}$.

\subsection{Application of new materials}

At present, the society is beginning to pay attention to the development and value of organic and biomimetic materials, as well as the design performance, cycle life and recovery performance of man-made materials. Designers believe that science and biology are brewing a leap into invisible materials and organic experiments and technologies to promote the construction of new sustainable buildings ${ }^{[5]}$.

The famous architect Stephen Hall has independently developed a brand new porous building material with light brown digital perforated plates. People can glimpse through the perforated panels to see plants or landscapes planted inside or outside the building.

Among the modern composites, the most versatile is the ETFE (ethylene-tetrafluoroethylene copolymer) film. The large-scale public buildings such as the Beijing National Stadium "Bird's Nest" and the National Aquatics Center "Water Cube" also used the ETFE membrane structure. This material can be machined to any size and shape to meet the needs of large spans, saving the intermediate support structure. It can adjust the shading and light transmission by controlling the amount of air, effectively use natural light, save energy and play a thermal insulation roleat the same time.
In architectural design, we advocate the use of bionic materials, because the construction of biomimetic materials not only makes the building façade innovative, but also to some extent effectively achieve the energy-saving effect of the building. For example, honeycomb foam concrete is a new type of energy-saving concrete material created by humans to mimic the characteristics of honeycomb structure. Foam glass, foam rubber, foam concrete, aerated concrete and other materials are artificial bionic materials designed by humans according to the structural form of honeycombs and ant 's cave.

German scientists have used the biological principle of chameleon skin to develop a color-changing glass with a "Collective temperature sensitive layer", this glass imitate the biological properties of the chameleon skin to change the transparency with the temperature of the outside world, thereby controlling the brightness and temperature inside the building.

\subsection{Combination of material and construction technology}

When using different materials for architectural facades, we must be good at using different construction techniques. Even with the same materials, if different construction techniques are used, the façade molding of the buildings that are presented may vary greatly. For example, when the exterior wall of a building is veneered, it is not necessary to be regular and leveled.

In the collage construction, we can combine the texture changes of the masonry and the changes of the building wall, and appropriately change the construction method, giving the traditional masonry wall a brand new image. Mario Botta is especially good at using a variety of different construction techniques. In his architectural works, the various uses of bricks have been tried almost, sometimes large-area brick walls everywhere, sometimes extremely complicated masonry pattern ${ }^{[7]}$.

The "Seed Temple" in the British Pavilion building of the 2010 Shanghai World Expo symbolizes the future green city. The cube-shaped building is filled with about 60,000 transparent acrylic rods containing plant seeds. These acrylic rods stretch outwards, making the building look like a "dandelion." During the day, the light illuminates the interior of the "Seed Temple" through the transparent acrylic rod; at night, the light source inside it illuminates the entire building. The entire building is equipped with new materials and technologies that make it amazing with aprofound connotation.

The facade of the Starhill Gallery Shopping Center in Kuala Lumpur, Malaysia designed by SPARK uses lightweight steel, stone and glass materials combined with the high-end facade technologies of French RFR Engineering Company to form a crystalline facade around the existing buildings creates continuous playful building texture. It resembles the "veiling" on the ancient statues of Greece and Romesculptures, and the whole building stands out in the surrounding buildings.

The sloping roof of the new headquarters building in St. Gallen, Switzerland, relies on the addition of fiber 
technology to the concrete mold to increase the viscosity of the cement and thus the stability of the building. The dark tone perforated Titanium zinc plate installed with the semi-structured facade of the building undergoes a unique coloring process, which makes the gloss flicker at different times, and the building is interesting ${ }^{[7]}$.

\section{Structural technology innovation}

\subsection{Develop new structural technologies}

Digging the potential of mechanics and aesthetics from the traditional structural form and applying it to the exterior design of the building is a major approach to the innovative design of the building facade. We can use component replacement technology, parameter transformation technology, interface bending technology, various structural coordination or new structure to achieve the innovation of building facade modeling.

When designing the Shenzhen Vanke Center, the American architect Steven Holl boldly improved the traditional structural system based on its traditional structural system, and created a hybrid structure system with a variety of framework structure and cable structure system. It not only improves the overall force-bearing capacity of the building, but also makes the building a new form.

Santiago Calatrava, the world's most famous innovative architect, has been working on a new architectural structure system. He pays attention to structural system optimization, and is good at using adjustable, changeable and flexible structure to create a new architectural space that satisfies the composite function. He is good at finding the best combination point in structure, artistic effect, material and economy to achieve the most reasonable structure, the lowest material consumption and the highest economic benefits. The Art Museum of Milwaukee, designed by Calatrava, not only attracts attention to its architectural style, but also uses an adjustable and variable structure. Its movable roof is equipped with natural sensing devices, which not only regulates the light in the building, but also has strong sensitivity to sunlight and wind direction. When the wind speed exceeds the predetermined value, the roof will automatically close, as if a giant bird Collapsing the wings $^{[8]}$.

Nature is the teacher of human beings. The living creatures survived by the survival of the fittest have a reasonable and perfect physiological structure, external form, internal function or texture, which gives architects the inspiration for architectural structure innovation, brings a lot of inspiration to the design of the building facade.

As a modern architect, we should be good at using our keen perspective to observe the ecological environment, draw inspiration from the physiological structure, external form, texture and function of animals and plants, and integrate modern science technology to apply bionics to architectural design. The "City Cactus" bionic cactus in Rotterdam the Netherlands, the curves of the building's exterior are not only creative, but also make the outdoor space of each unit get enough sunshine. The Indian Lotus Temple (Bahai Temple) is a bionic Indian national flower and a Hinduism holy flower lotus. The whole building is beautiful and unique. The function, structure and spiritual symbol of the building are perfectly integrated.

\subsection{Combination of various structural technologies}

In the architectural design, we can use a variety of structural technology to achieve the effect of building elevation modeling innovation. The columbus international exhibition hall designed by Italy's famous architecture Renzo Piano of is the use of a variety of structural systems. The building uses membrane structure system, truss structure system, suspended element structure system and steel arch structure system, not only create a new architectural form, but also create a variety of lively and a full of fantastic colors of architectural space.

The combination of the steel tensile structure and the membrane structure is an innovative design, which makes the structure of the whole building not only have greater rigidity, the architectural appearance has a strong artistic appeal, but also the interior forms a huge column-free space, improving the indoor flexible application.

\section{Other technological innovations}

In today's society, science and technology are developing rapidly, various new technologies are emerging. Architects can appropriately apply different new technologies according to the nature and actual conditions of the building when designing the appearance modelling of a building. Using modern advanced computer-aided design and data-controlled manufacturing technology, we can design and implement innovative building facades. By analyzing the complex geometric structure of the building, the architect uses the 3D data model of the BIM concept to design a unique building. Regardless how complex of building components, as long as describe accurately by computer digitized information, digital control technology can ensure the accurate conversion of computer graphics and digital information into materialized building components ${ }^{[9]}$.

We can innovate architectural shapes by using modern advanced energy-saving technologies, the Administration Building in London designed by Foster \& Partners is a typical case. Its compact deformation sphere reduces the building surface area, reduces solar heat radiation in summer, reduces heat loss in winter, and improves energy efficiency. The floor slabs of the south of the building are overhanging layer by layer, which not only can cover the outer surface of the lower building, avoid direct sunlight, but also make the exterior façade of the building full of features.

We can innovate architectural shapes by using daylighting technology or ventilation technology. The Stuttgart train station in Germany uses a combination of "light eye" (supported by a steel mesh and concrete support skeleton plus a transparent film) to achieve 
natural lighting and create a unique and innovative architectural exterior ${ }^{[10]}$. The Swiss Reinsurance Tower in London is based on the consideration of natural ventilation and orderly flow of air to create a distinctive personality architectural style. The building adopts a bullet-shaped curve shape, which not only can decelerate and weaken the airflow, but also achieve good natural ventilation in the interior. The overall molding of the building is not only beautiful and creative, but also avoids strong wind and downward swirling airflow.

In addition, we can also use the self-illuminating electronic components to transmit image information to the outside world on the façade of the building, use the LED dynamic scale light source to form the architecture dynamic light source, use the openable roof technology to design the roof of the building, use Semi-transparent or fully transparent materials such as glass, film materials to form the façade of the building transparent or lighting changeable, use the woven material to woven the building skin to form a rich light and shadow change, use the light-proof perforated material design or hollowed design to form a virtual and real coexistence building appearance and so on

\section{Conclusions}

Architectural design innovation is the need of the times, and the development of architectural design is inseparable from the innovation of architectural design.

Today, with the rapid development of science and technology, as an architect, if he lacks the ability to innovate, he will be in a disadvantaged position in the competition. In summary, we can innovate the design of the facade molding of the building from the basic elements of the design, architectural details, materials and technology, structural technology and other technologies. At the time of design, we can use one aspect or several methods above to create. In the future, we will continue to research and expand new innovations in design to provide a broader perspective for future architectural design.

\section{Acknowledgement}

This paper is the research result of the 2017 Guangdong Provincial Department of Education Provincial Project
"Application Research of Lingnan Traditional Elements in Modern Architectural Design" (The research subject number is 2017GkQNCX125) and the 2018 Guangzhou Nanyang Polytechnic College's school-level research subject "Study on Architectural Design Innovation Design and Application" (The research subject number is NY-2018KYYB-12).

\section{References}

1. Wang Cambodia. Research on the application of polyline elements in modern architectural form design [D]. Harbin Institute of Technology, 2014.

2. Shen Tao. Research on architectural morphological characteristics based on giant truss structure technology [D]. Tianjin University, 2017.

3. [U.S.] Judy A. Juric. The design elements of architectural skin designers and artists [M]. Da Lian: Dalian University of Technology Press, 2010.

4. Wang Pengpeng. Research on the shared space and modeling design of college comprehensive buildings in University [D]. Southeast University, 2015.

5. [U.S.] Beverly Russell, Eva L. Maddox, Farouk Amin. The world famous architects innovative works collection [M]. Guangxi Normal University Press, 2015.

6. Lu Boda. Research on the innovative design of contemporary stadium roof shape [D]. Harbin Institute of Technology, 2015.

7. Long Zhiwei. Innovative architectural modeling [M] Guangxi: Guangxi Normal University Press, 2014.

8. Zheng Quanyi. Research on Architectural Design Innovation of the 21st Century AIA Architecture Gold Award Winners [D]. Harbin Institute of Technology, 2012.

9. Ji Xiang. Building skin language [M]. China Building Industry Press 2012.

10. Liu Min, Liu Yi, Liu Qian. Green Building Technology and Architectural Model Design [J]. Forestry Science and Technology Information, 2013 